\title{
Evaluation of the Reasons for the Choice of Their Learning Course by Resident Physicians of Anesthesia and Intensive Care Medicine (ICU) in Mali
}

\author{
Abdoulhamidou Almeimoune ${ }^{1,2 *}$ (D) Moustapha Mangane ${ }^{1,2}$, Diop Madane Thierno ${ }^{1,2}$, \\ Seidou Alaji Démbele ${ }^{2,3}$, Sirman Koita ${ }^{2,4}$, Mahamadoun Coulibaly ${ }^{2,4}$, Youssouf Sogoba ${ }^{2,5}$, \\ Kalba Tembine6, Mamadou A. C. Cisse ${ }^{2,6}$, Harouna Sangare', Sidy Yattara1, André Kassogue1, \\ Boubacar Diallo7, Hammadoun Dicko', , , Djibo Mahamane Diango',2, Youssouf Coulibaly2,7 \\ ${ }^{1}$ Department of Anesthesia, Intensive care and Emergency Medicine of CHU Gabriel Touré, Bamako, Mali \\ ${ }^{2}$ Faculty of Medicine and Odontostomatology of Bamako, Bamako, Mali \\ ${ }^{3}$ Anesthesia and Intensive Care Unit CHU IOTA, Bamako, Mali \\ ${ }^{4}$ Anesthesia and Intensive Care Unit CHU, Bamako, Mali \\ ${ }^{5}$ Neurosurgery Service at CHU Gabriel Touré, Bamako, Mali \\ ${ }^{6}$ Emergency Department of Mali Hospital, Bamako, Mali \\ ${ }^{7}$ Department of Anesthesia, Resuscitation and Emergency Medicine of the CHU Point G, Bamako, Mali \\ Email: *abdoulhamidoumaiga@gmail.com
}

How to cite this paper: Almeimoune, A., Mangane, M., Thierno, D. M., Démbele, S. A., Koita, S., Coulibaly, M., Sogoba, Y., Tembine, K., Cisse, M. A. C., Sangare, H., Yattara, S., Kassogue, A., Diallo, B., Dicko, H., Diango, D. M., \& Coulibaly, Y. (2022). Evaluation of the Reasons for the Choice of Their Learning Course by Resident Physicians of Anesthesia and Intensive Care Medicine (ICU) in Mali. Creative Education, 13, 320-328. https://doi.org/10.4236/ce.2022.131019

Received: November 8, 2021

Accepted: January 25, 2022

Published: January 28, 2022

Copyright $\odot 2022$ by author(s) and Scientific Research Publishing Inc. This work is licensed under the Creative Commons Attribution International License (CC BY 4.0). http://creativecommons.org/licenses/by/4.0/

\section{Open Access}

\begin{abstract}
Anesthesia and intensive care is a medical specialty of the third cycle of medical studies characterized by a diversified practical training and an important theoretical training little approached during the second cycle of medical studies. In Mali, this young medical discipline is still looking for its bearings. we felt it was imperative to evaluate the motivations behind the choice of their apprenticeship program in order to understand the reasons behind the collapse of the numbers recruited and the dropouts during the program. $\mathrm{Pa}$ tients and Method: We conducted a prospective study using a self-administered questionnaire in the population of residents in Anesthesia and Intensive Care at the Faculty of Medicine of the Bamako University. Our study was conducted during the 2018-2019 academic year. An anonymous questionnaire was' sent by email to all students of anesthesia-resuscitation of the specialized study diploma of Mali during the month of April 2019. Results: A total of $16 / 25$ complete questionnaires were completed and returned that's to say a response rate of $64 \%$. Two-thirds $(62 \%)$ of the residents had already attended the anesthesia-intensive care sector during the second cycle of medical studies before their admission to the specialty probationary period. Versatility, intel-
\end{abstract}


lectual interest, emergency management, and technical aspect seemed to be the most attractive elements of the specialty. The points that might have made residents hesitate when choosing the specialist were the medico-legal risk, the important on-call activity, and the poor quality of life in the long term. Also, $12 \%(\mathrm{n}=2)$ were considering changing their specialized study diploma. Half of the residents were considering a professional practice in a public university hospital (50\%), for $25 \%$ this choice was for the private sector and $12 \%$ in the humanitarian sector. On-call duty was perceived as formative for $75 \%$ of the anesthesia and intensive care students, while $18 \%$ of them considered it too numerous or even painful for $25 \% .80 \%$ of the residents observed safety rest. During their internship in the different hospitals, the most appreciated points were, among others, their autonomy of decision, and the most negative were the fact of being too often alone. Residents in anesthesia-intensive care wished to have a depth training in locoregional anesthesia for $56 \%$ and pediatric anesthesia for $31 \%$. Conclusion: Despite a relevant motivation for their choice, the difficult living and learning conditions were a source of demotivation for the anesthesia residents in Mali.

\section{Keywords}

Initial Training, Intensive Care Anesthesia, Organization, Pedagogy, Mali

\section{Introduction}

Anesthesia-intensive care is a medical specialty of the third cycle of medical studies characterized by a diversified practical training and a significant theoretical training little approached during the second cycle of medical studies (DCEM in french) (Perbet et al., 2010). In Mali, this young medical discipline is still in the process of finding its bearings. Mali is one of the 14 countries in sub-Saharan Africa French-speaking. In this region, the total population was estimated in 2014 at 241,300,000 inhabitants (Bougma, 2010; Beck et al., 2018). Three hundred and sixty-nine Anesthesiologists-Resuscitators doctors have a regular practice there with a ratio of 1.6 anesthesiologists per million inhabitants (Sanou et al., 1999; Zoumenou et al., 2015). The medical demographics in anesthesia and intensive care in the region are 100 times lower than that observed in France (Zoumenou et al., 2015). Most Malian anesthesiologists were trained in two French-speaking sub-Saharan African countries with a special studies certificate in anesthesia-resuscitation (Senegal and Ivory Coast) in this lack of anesthesiologist context, it appears imperative and urgent to create an initial training course in anesthesia and intensive care in order to satisfy the growing needs for anesthetic act.

However, the attractiveness of this new training remained a constant concern for the society of anesthesia, intensive care and emergency medicine of Mali (SARMU-Mali in French), as for many other authors (Nicolas \& Duret, 1998; Bart et al., 2008; Wass et al., 1999; Jackson, 1999).

In Mali, anesthesiologist job was formerly performed by nurse anesthetists 
trained on the heap, that's why a disinterest risk in the discipline by young doctors leaving medical school. However, the first two promotions of anesthesiologist resident recruited 15 residents each one and suddenly in 2013, we witnessed a sharp downfall in the number of recruited staff (on average 2 per promotion) and dropouts during the course. In front of this recruitment downgrade, it seemed imperative to us to assess the motivations behind the choice of their learning course in order to understand the reasons underlying the collapse of the recruited workforce and the dropouts of training during the course.

\section{Methodology}

\subsection{Study Seat}

We conducted a prospective study among the population of anesthesia-resuscitation residents of the Faculty of Medicine from the Technical and Technological Sciences University of Bamako (USTTB). Mali has only one faculty of medicine in charge for teaching the 3rd cycle of medical studies including Anesthesia-resuscitation special study diploma (DESAR in French). They are apportioned in 5 bigger hospitals in Bamako for a validating internship of 6-month on a rotating basis. In each hospital and according to their level (number of semesters), they are assigned educational objectives. It should be mentioned that access to Anesthesia-resuscitation special study diploma is conditioned on to the probationary examination success and payment of annual tuition fees of 450,000 CFA francs (686.83 Euros). During their training, resident doctors in anesthesia-resuscitation are not rewarded and alone bear the costs of their training during the four years of their course.

\subsection{Inclusion Criteria}

Were included residents specializing in anesthesia, resuscitation registered at the faculty of medicine, practicing hospital clinical internship who answered our questionnaire.

\subsection{Non-Inclusion Criteria}

Residents admitted to the probationary but not having started hospital placements were not included.

\subsection{Conduct of the Investigation}

Our study was conducted during the 2018-2019 academic year.

An anonymous questionnaire was sent by email to all Anesthesia-resuscitation resident in Mali during the month of April 2019.

\subsection{Parameters Studied}

Demographic information (age, sex, original university hospital, year of admission to the probationary, current semester, marital status, children, housing and living conditions). 
$\checkmark$ The choice of career (completion of internships during the second cycle of medical studies in the resuscitation sector, anesthesia, emergencies, pain, order of choice of specialty and positive and negative elements of the choice of specialty, exercise mode in the long term, criteria influencing the choice of installation location).

$\checkmark$ Theoretical training (carrying out a scientific training: master's, doctorate ... or additional medical: inter-university diploma, additional specialized study diploma: medical resuscitation, emergency medicine ..., average expenditure devoted to learning, subscription to the scientific journal, fluency in English, presence of staff, courses, regular bibliographies in the services, congress participation, contribution to a scientific publication, wishes expressed, overall opinion).

$\checkmark$ Practical training: (application of safety rest, the course carried out, on-calls perception, the carrying out and the feeling of semester during the rotation in a university hospital center [UHC] or in liberal sector, their training evaluation about locoregional anesthesia [LRA], ultrasound practice and the ultrasound training wish, overall opinion).

\subsection{Analysis Plan}

Excel 2010 software was used for data processing. The analysis mainly consisted of the realization of averages and percentages. A $\mathrm{z}$ test or Student test, depending on the series, was used to compare two averages and a Chi2 to compare two percentages. A $p$ value $<0.05$ was then retained as significant.

\section{Results}

Overall, 16/25 completed questionnaires were filled out and returned, either a response rate of $64 \%$. There was a male predominance with a sex ratio of 3 . For the year 2018-2019, 2 dropouts and 1 postponement to the 2nd year of Anesthesia-resuscitation special studies diploma were reported to us by the Anesthesia-resuscitation special studies diploma coordination (Table 1).

The average age of residents was 31 years old with extremes of 25 years to 41 years. The large majority (81\%) of residents in anesthesia-resuscitation lived as a couple, of which $56 \%$ resided in the same city as their wives. Half (56\%) of residents in Anesthesia-Resuscitation lived in individual housing in the city against

Table 1. Demographic information.

\begin{tabular}{cccc}
\hline Class & Number by class $(\mathrm{n})$ & Number of interviewees $(\mathrm{n})$ & Response's rate \\
\hline $1^{\text {st }}$ year & 7 & 7 & $100 \%$ \\
$2^{\text {nd }}$ year & 3 & 1 & $33 \%$ \\
$3^{\text {rd }}$ year & 14 & 7 & $50 \%$ \\
$4^{\text {th }}$ year & 1 & 1 & $100 \%$ \\
TOTAL & 25 & 16 & $64 \%$ \\
\hline
\end{tabular}


$6(21 \%)$ with parental family. Fifty percent of residents were unpleased with their living conditions.

\subsection{Motivations for Career Choice}

Two-thirds (62\%) of residents had already attended the Anesthesia-Resuscitation sector during the second cycle of medical studies before their admission to the specialty probationary, either $20 \%$ in intensive care and $37 \%$ in emergency while $31 \%$ of future residents had never completed an internship in the Anesthesia-Resuscitation and emergency sector. Versatility, intellectual interest, emergency management and the technical complexion seemed to be the most attractive elements of the specialty (Figure 1).

\subsection{Negative Perception of Training}

The explaining factors of the demotivation in their choice were the medico-legal risk, the heavy on-call activity, and the worse quality of life, $12 \%(n=2)$ thought of changing special study diploma. The most important criteria intervening in the choice of the future workplace were the optimal conditions (43\%) for practicing medicine, life quality at $37 \%$ and personal history $24 \%$. Half of the residents contemplated a professional exercise in a public university hospital (50\%), for $25 \%$ this choice involved the liberal sector and $12 \%$ in the humanitarian sector. the activity sector wished in the long term was multipurpose resuscitation in $50 \%$ cases, anesthesia in $31 \%$ cases.

\subsection{Theoretical Training}

Seventy-five percent (75\%) were considering an additional non-medical degree to their university education, without specifying the type in $38 \%$ of cases (Figure 2).

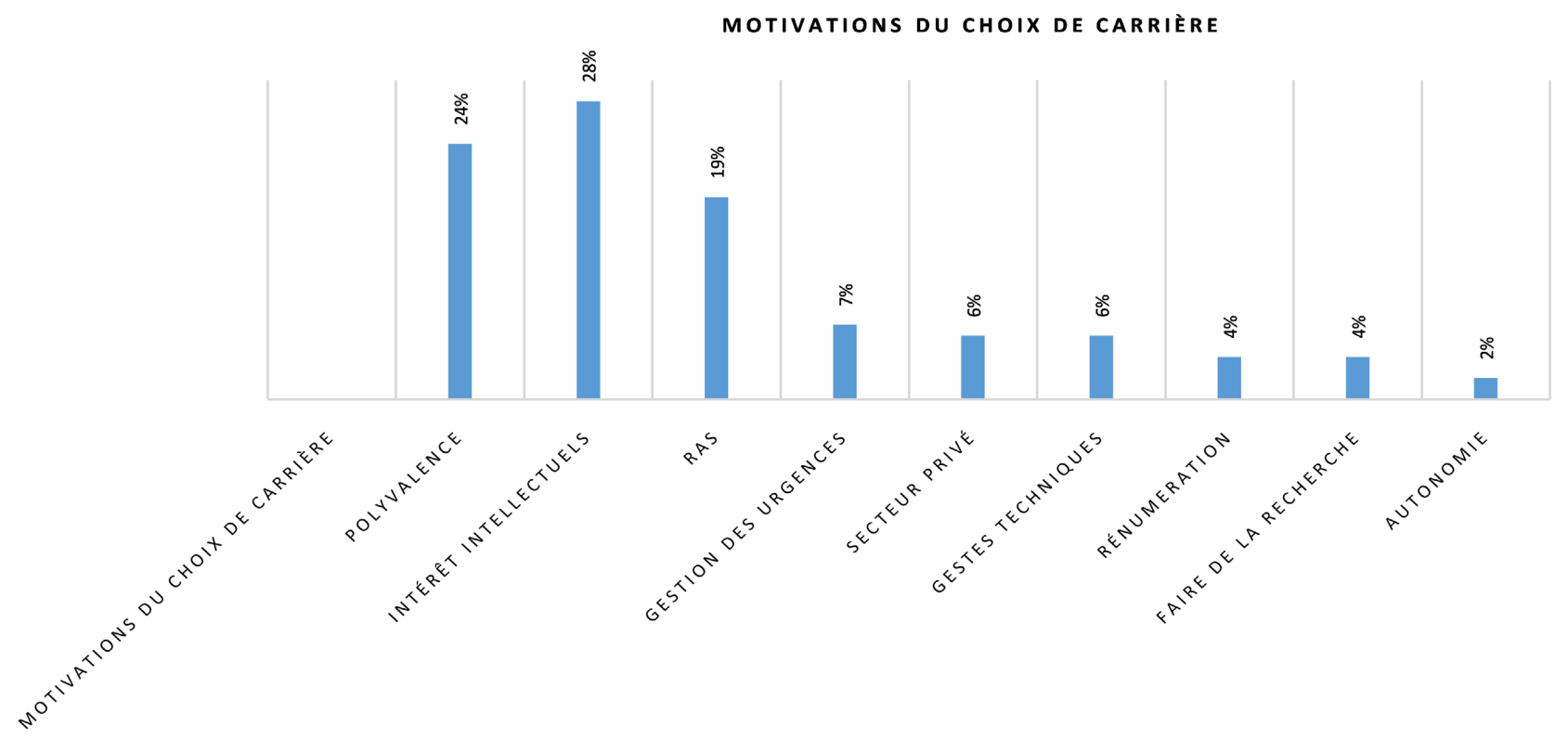

Figure 1. Choice motivation. 
Intention de realisation additional specialized study diploma (DESC)* non médical ( $n$ )

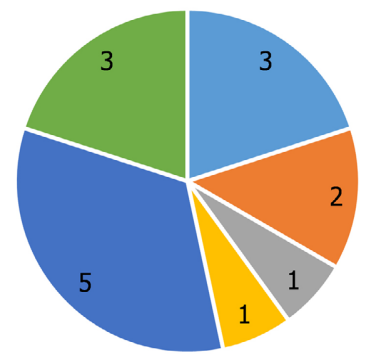

$\begin{array}{lll}- \text { MASTER } 2 & =\text { THESE DE SCIENCE } & =\text { PEDAGOGIE } \\ - \text { GESTION ENTREPRISE } & - \text { ENVISAGE SANS PRECISION } & =\text { NON ENVISAGE }\end{array}$

Figure 2. Intention to carry out a DESC. ${ }^{\star}$ Additional specialized study diploma (DESC in French).

For $25 \%$ this choice concerned a master's 2 and for this $16 \%$ it was a science thesis, on the other hand, no residents in Anesthesia-resuscitation had completed or obtained an additional specialized study diploma or IUD. Only 18\% Anesthesia-Resuscitation residents stated that they had subscribed to a scientific journal without specifying the type of journal and a third was member of the anesthesia, resuscitation and emergency medicine society of Mali (SARMU-MALI).

\subsection{Practical training}

The guards were seen as formative for $75 \%$ of the interviewees, while $18 \%$ had considered them too numerous or even painful for $25 \%$. Safety rest was observed at $80 \%$ by residents. During their internship in the different university hospitals, the most appreciated points were among others their self-governing of decision, and the most negative points were being too often alone. Their opinion about hospital internships was pretty good for $50 \%$ ditto for management. No resident uses ultrasound in routine practice while only $18 \%(n=3)$ had profited from a workshop about learning ultrasound in anesthesia organized by SARMU-Mali, in this context almost all of residents wanted specific training in ultrasound.

Residents in Anesthesia-Resuscitation wanted in-depth training in locoregional anesthesia for $56 \%$ and in pediatric anesthesia for $31 \%$. Eighty-seven percent of residents wanted an experience outside Mali. All residents were agreeing for a practical assessment in clinical position. Practical training was rated good for $56 \%$ and insufficient for $18 \%$. Half of the residents wouldn't like do again the probationary in Anesthesia-Resuscitation.

\section{Discussion}

The anesthesia-resuscitation special study diploma in Mali was an attractive and motivating specialty at its beginning, however it tends to lose this asset over the years that follow one another as evidenced by the probationary student's number decreasing and the dropping out cases during the course. Yet the demographics and training of practitioners are of paramount importance among the contri- 
buting factors to improving the quality of anesthesia-resuscitation care. The situation in poor countries is different from that of developed countries, especially which concern the practitioners training. In our case, the students in training were not satisfied with their learning conditions in view of the lack of financial remuneration and the training burden in terms of validating hospital internship, compulsory theoretical class and the on-calls in hospital. These difficult training conditions should raise concerns about the professional exhaustion syndrome or burnout because according to several authors (Mion et al., 2010; Bouaziz et al., 2013). The population of anesthetists-resuscitators constitutes a most cohort at risk according to its workload, the need to make urgent decisions, the pace of on-call duty and direct responsibilities on patients' lives. While it is true that there are many obstacles to the attractiveness of training in anesthesia-resuscitation, it is undeniable substantial progress has been made in the medicalization of it. Actually, since the creation of anesthesia-resuscitation special study diploma in Mali, the demography of anesthetist-resuscitator doctors has experienced a considerable increase of around $340 \%$ over the last five years, from 14 to 48 practitioners.

This finding differs from the observation made in France by Perbet et al. (2010) where the Anesthesia-Resuscitation inter has become more attractive and where interns are rewarded monthly and their on-call paid.

We note a great ambition of anesthesia-resuscitation residents for their theoretical training, in fact $3 / 4$ envisaged a non-medical supplement to their university diploma even if no one has carried out an Additional Special Study Diploma (DESC in French), however it should be said that the offer of additional training is very poor in the Malian university context, this observation has already been made by Zoumenou et al. (2015) which denounced the total lack of specific training offer like an university diploma (UD) in French-speaking sub-Saharan Africa. Despite the application of post-guard security rest and respect for its observation, a quarter of residents found the on-calls painful, this arduousness could be explained by the drudgery represented by the public hospital's on-calls because unpaid, this feeling is accentuated by the fact of being too often left alone during their internship and the almost permanent contact with death, permanent stress with its paroxysms, the lack control of working time, extended hours (Roudaut et al., 1994).

Residents in Anesthesia-Resuscitation had a good opinion of their practical training but it was clear that they have no current practice in ultrasound and moreover eagerly wanted specific training on this practice. Ultrasound is today an essential tool for patient care in distress, both in the emergency room and in intensive care. This tool is no longer reserved for radiologists and covers very wide application fields: Abdomen, thorax, hemodynamics, nervous system, interventional procedures. The relevance of this observation justifies the drafting of standards and recommendations by several learned societies (Pearlman et al., 1992; Vignon \& Guéret, 2004) about the physician's training ultrasonic technique. This concern was shared by the coordination of the anesthesia-resuscitation 
special study diploma and intended to compensate that shortfall from the start of following academic year. Ultrasound devices are already acquired by the coordination of the anesthesia-resuscitation special study diploma. The locoregional anesthesia and pediatric anesthesia practice remains marginal for lack of a specialized center, which could explain the fiery wish of anesthesia-resuscitation residents to profit from an experience outside Mali.

We have observed that the population is getting feminized over the years because it was exclusively male during the first two promotions. According to Lapeyre \& Le Feuvre (2005), this is probably due to an overall feminization phenomenon of medical studies. In our context, this feminization of anesthesia-resuscitation could be explained by the greatest opportunity of job offers in this medical specialty in urban environment contrary to other disciplines, where the employment opportunities are considered in the long term more in the rural environment.

Even if the students were studied in the courses, the development of the MOOCs is a chance to put the theoretical lessons online.

\section{Conclusion}

Despite their choice motivation based on the intellectual concern and the technicality of the discipline, the woeful living and learning conditions associated with the on-calls drudgery constitute a barrier for the discipline attractiveness. In order to ensure the attractiveness of this training, it would be advisable to create an educational simulation center in anesthesia and critical care to overcome the lack of tutoring during on-call duty at the hospital.

\section{Conflicts of Interest}

The authors declare no conflicts of interest.

\section{References}

Bart, F., Laigle, C., \& Dupont, H. (2008). Évaluation de la formation des internes en anesthésie réanimation et en anesthésie loco-régionale. Annales Françaises d'Anesthésie et de Réanimation, 27, s222. https://doi.org/10.1016/j.annfar.2012.04.007

Beck, B., Marcoux, R., Richard, L., \& Wolff, A. (2018). Estimation des populations francophones dans le monde en. Sources et démarches méthodologiques. Observatoire démographique et statistique de l'espace francophone. Québec: Université Laval, Note de recherche de l'ODSEF, $160 \mathrm{p}$. https://www.odsef.fss.ulaval.ca/sites/odsef.fss.ulaval.ca/files/odsef-lfdm-2018.pdf

Bouaziz, H., Aubrun, F., Belbachir, A., Cuvillon, P., Eisenberg, E., Jochum, D., Aveline, C., Biboulet, P., Binhas, M., Bloc, S., Boccara, G., Carles, M., Choquet, O., Delaunay, L., Estebe, J.-P., Fuzier, R., Gaertner, E., Gnaho, A., Nouette-Gaulain, K., Nouvellon, E., Ripart, J., \& Tubert, V. (2013). Ultrasound-Guided Regional Anesthesia. Annales Françaises d'Anesthésie et de Réanimation, 32, e119-e120. https://doi.org/10.1016/j.annfar.2013.07.790

Bougma, M. (2010). Dynamique des langues locales et de la langue française au Burkina Faso: Un éclairage à travers les recensements généraux de la population (1985, 1996 et 2006). Rapport de recherche de I'ODSEF, Observatoire démographique et statistique de 
l'espace francophone. Québec: Université Laval, 61 p. https://www.odsef.fss.ulaval.ca/sites/odsef.fss.ulaval.ca/files/odsef_rrmbougma2010._18 022010_110928.pdf

Jackson, S. H. (1999). The Role of Stress in Anaesthesist's Health and Well-Being. Acta Anaesthesiologica Scandinavica, 43, 583-602. https://doi.org/10.1034/j.1399-6576.1999.430601.x

Lapeyre, N., \& Le Feuvre, N. L. (2005). Féminisation du corps médical et dynamiques professionnelles dans le champ de la santé. Revue Francaise des Affaires Sociales, 1, 59-81. https://doi.org/10.3917/rfas.051.0059 https://www.cairn.info/revue-francaise-des-affaires-sociales-2005-1-page-59.htm

Mion, G., Libert, N., Petitjeans, F., \& Journois, D. (2010). Burn out en anesthésie-réanimation. In Enjeux éthiques en reanimation (pp. 201-207). Springer. https://doi.org/10.1007/978-2-287-99072-4_21

Nicolas, G., \& Duret, M. (1998). Rapport sur l'adéquation entre les besoins hospitaliers en anesthésie-réanimation, gynécologie-obstétrique, psychiatrie et radiologie. Annales Françaises d'Anesthésie et de Réanimation, 17, fi53-fi67. https://doi.org/10.1016/S0750-7658(98)80017-8

Pearlman, A. S., Gardin, J. M., Martin, R. P., Parisi, A. F., Popp, R. L., Quinones, M. A. et al. (1992). Guidelines for Physicians Training in Transesophageal Echocardiography: Recommendations of the American Society of Echocardiography Committee for Position Training in Echocardiography. Journal of the American Society of Echocardiography, 5, 188-194.

Perbet, S., Eisenmann, N., Constantin, J.-M., Colomb, S., Soummer, A., Jaber, S., \& Bazin, J.-E. (2010) Évaluation des motivations de choix et de leur cursus d'apprentissage par les internes d'anesthésie-réanimation: Enquête nationale. Annales Françaises d'Anesthésie et de Réanimation, 29, 93-103. https://doi.org/10.1016/j.annfar.2009.10.026

Roudaut, R., Touche, T., Cohen, A., Cornier, B., Dehant, P., Diebold, D. et al. (1994). Recommandations de la Société française de cardiologie concernant la formation des échocardiographistes et la réalisation des échocardiogrammes. Archives des Maladies du Coeur et des Vaisseaux-Pratique, 87, 791-798.

Sanou, I., Vilasco, B., Obey, A., Binam, F., Chobli, M., Touré, M. K., \& Adnet, P. (1999). Évolution de la démographie des praticiens d'anesthésie en Afrique francophone au sud du Sahara. Annales Françaises d'Anesthésie et de Réanimation, 18, 642-646. https://doi.org/10.1016/S0750-7658(99)80151-8

Vignon, P., \& Guéret, P. (2004). Formation des réanimateurs à l'échographie cardiaque. Réanimation, 13, 126-130. https://doi.org/10.1016/j.reaurg.2003.10.015

Wass, C. T., Rose, S. H., Faust, R. J., Offord, K. P., \& Harris, A. M. (1999). Recruitment of House Staff into Anesthesiology: Factors Responsible for House Staff Selecting Anesthesiology as a Career and Individual Training Program. Journal of Clinical Anesthesia, 11, 150-163. https://doi.org/10.1016/S0952-8180(99)00026-4

Zoumenou, E., Ndoye, M. D., Tchaou, B. A., Nguessan, Y. F., Kaboré, F., Diango, D., Chaibou, M. S., Bula, I. B., Essola, L., Otiobanda, G. F., \& Brouh, Y. (2015). Pratique de l'anesthésie chez l'enfant en Afrique francophone subsaharienne. État des lieux et perspectives d'amélioration. Anesthésie \& Réanimation, 1, 512-516.

https://doi.org/10.1016/j.anrea.2015.10.008 